\title{
Colon Cancer among Older Saudis: Awareness of Risk Factors and Early Signs, and Perceived Barriers to Screening
}

\author{
Yasmine Samir Galal ${ }^{*}$, Tarek Tawfik Amin ${ }^{1}$, Abdulelah Khalid Alarfaj², \\ Abdulaziz Abdullah Almulhim², Abdullah Abdulmohsen Aljughaiman ${ }^{3}$, \\ Abdulrhaman Khaled Almulla ${ }^{4}$, Rehab Ahmed Abdelhai ${ }^{1}$
}

\begin{abstract}
Background: Colon cancer screening (CRCS) uptake is markedly affected by public awareness of the disease. This study was conducted to assess levels of knowledge of CRC, to explore the pattern of CRCS uptake and identify possible barriers to screening among Saudis older than 50 years of age and primary care providers (PCPs) in Al Hassa region, Saudi Arabia. Materials and Methods: This cross-sectional study was conducted in randomly selected primary health care (PHC) centers, 884 Saudis and 39 PCPs being enrolled for data collection. Structured interviews were conducted to obtain information regarding socio-demographic characteristics, personal information relevant to $\mathrm{CRC}$, awareness about early signs/symptoms and risk factors, and barriers to CRCS. Also, a self- administered data collection form was used to assess barriers to CRCS from the physicians' perspectives. Results: More than $66 \%$ of participants were lacking knowledge about CRC. Participants with higher educational levels, having ever heard about $\mathrm{CRC}$, and having relatives with CRC had a significantly higher awareness of the disease. The rate of reported CRCS was low (8.6\%). After conducting a logistic regression analysis, it was observed that female gender $(\mathrm{OR}=0.28 ; 95 \% \mathrm{CI}=0.14-0.57 ; \mathrm{P}=0.001)$, being unmarried $(O R=0.11 ; 95 \% C I=0.10-0.23 ; P=0.001)$, lower levels of education $(O R=0.36 ; 95 \% C I=0.16-0.82 ; P=0.015)$, and having no relatives with $\mathrm{CRC}(\mathrm{OR}=0.30 ; 95 \% \mathrm{CI}=0.17-0.56 ; \mathrm{P}=\mathbf{0 . 0 0 1})$ were significantly associated with a lower CRCS uptake. There was a significant difference between most of the perceived barriers to CRCS and gender. Exploratory factor analysis showed that personal fear (especially fear of the screening results and shyness) was the major factor that hindered CRCS with high loading Eigen value of 2.951, explaining $34.8 \%$ of the barriers of the included sample toward utilization of CRCS, followed by lack of awareness of both person and providers (high Eigen value of 2.132, and explaining $23.7 \%$ of the barriers). The most frequently cited barriers to CRCS from the physicians' perspectives were lack of public awareness, lack of symptoms and signs, and fear of painful procedures. Conclusions: Poor levels of knowledge about CRC were found among older Saudis attending PHC centers in Al Hassa, Saudi Arabia. It is crucial to implement an organized national screening program in Saudi Arabia to increase public awareness.
\end{abstract}

Keywords: Colorectal cancer - risk factors - screening programs - barriers - public awareness

Asian Pac J Cancer Prev, 17 (4), 1837-1846

\section{Introduction}

Colorectal cancer (CRC) ranks the second most common cause of female cancer and the third most common cancer in males, worldwide (Lozano et al., 2012). There is a marked global variation in CRC incidence (Center et al., 2009), with higher rates being reported in developed countries compared to developing ones (Merika et al., 2010). Despite that there was an estimated 2-4 fold increase in the incidence of the disease over the past few decades (NG and Wong, 2013), public awareness and health care practices were inadequate for appropriate prevention and early detection (Sung et al., 2005).
According to the Saudi Cancer Registry (SCR) issued in 2014, CRC ranks the second after breast cancer among Saudi cancer patients and first among all male malignancies with a steady rise in incidence over the past few years (Al-Eid, 2014). Moreover, the overall survival rate in Saudi patients (44.6\%) is lower than that reported all over the world (Al-Eid and Al-Zahrani, 2007).

Risk factors of CRC include age of patients (50 years and older), family history, obesity, physical inactivity, metabolic syndrome, smoking, and non-alcoholic fatty liver disease (Amersi et al., 2005; NG and Wong, 2013). Early diagnosis of CRC by screening programs has been proven to reduce both the incidence and mortality of

${ }^{1}$ Public Health and Community Medicine, Faculty of Medicine, Cairo University, Cairo, Egypt, ${ }^{2}$ Department of Surgery, ${ }^{3}$ Department of Pediatrics, ${ }^{4}$ Department of Family Medicine, College of Medicine, King Faisal University, Riyadh, Saudi Arabia *For correspondence: yasminegalal@hotmail.com 
the disease (Christou and Thompson, 2012; Bidouie at al., 2014). Premalignant adenomatous polyps can be discovered and removed by screening (Zauber et al., 2012). Among all cancers, CRC is ideal for screening due to its high incidence rates and long duration between early and advanced stages (Mack et al., 2004). Involvement of primary health care (PHC) and family physicians in screening programs implementation has been recommended by several studies (Federici et al., 2005; Demyati, 2014) as they have a major role in screening practice due to their frequent contact with large groups of the population.

Unfortunately, CRC screening (CRCS) uptake is lower than that of other screening-amenable cancers worldwide (Joseph et al., 2012). In Saudi Arabia, despite the availability of resources for diagnosis of CRC; there is lack of consistent organized screening programs on the national level. Moreover, the knowledge of the population is less than required to encourage the spread of screening behavior (Khayyat and Ibrahim, 2014).

Factors affecting screening compliance can be grouped into patient, health care system, provider, and policy factors (Gimeno Garcia, 2012). Numerous patient barriers to CRCS have been identified in the literature;including personal fears, financial problems, lack of knowledge about the symptoms, signs, risk factors, outcome of the disease, and the benefits of screening (Klabunde et al., 2006; Berkowitz et al., 2008; Sung et al., 2008; Koo et al., 2010). However, fewer studies have been able to identify the barriers from the health care providers' perspectives (Hoffman et al., 2011; Demyati, 2014). To the authors' best knowledge, no study has been conducted in Saudi Arabia to explore the possible barriers to CRCS among the Saudi adults and the PHC providers as well.

The objectives of this cross-sectional study were to assess the level of knowledge towards signs and risk factors of CRC, to explore the pattern of CRCS uptake and identify the possible barriers to screening among Saudi adults aged 50 years or more in Al Hassa region, Saudi Arabia. Moreover, the study aimed at exploring the possible screening barriers from the primary care providers' (PCPs) perspectives.

\section{Materials and Methods}

Setting and design: A cross-sectional study that was carried out in Al Hassa Governorate, Eastern Province of Saudi Arabia; located $50 \mathrm{~km}$ from the Arabian Gulf, 450 $\mathrm{km}$ from the capital Riyadh, and populated by about 1.5 million. Al Hassa is comprised of three regions; urban, populated by about $60 \%$ of the total population, rural consisting of 23 villages ( $35 \%$ of the population) and "Hegar" Bedouin scattered communities making up the remaining 5\%. The Ministry of Health provides primary care through 54 PHCs, while the rest of the population are provided with similar services through other sectors e.g., National Guard, ARAMCO (oil company), military and others.

Population: Adult Saudis of both genders aged $\geq 50$ years attending PHC centers in both urban, rural and Hegar (beduin) areas in Al Hassa and PCPs at the selected
PHC centers.

Sample size: Epi-Info version 7.1.5 (CDC, Atlanta, GA, U.S.A.) was used to calculate the sample size required. Assuming prevalence of knowledge about colon cancer of $37 \%$ (Khayyat and Ibrahim 2014) among adult Saudis aged $\geq 50$ years registered at primary care level (about 300,000 according to the local Health Directorate year 2012), with a precision of $\pm 5 \%$, and design effect of 2.0 while employing a $95 \%$ confidence interval and $80 \%$ power, the minimal sample size required was 716 participants. Adding $20 \%$ to compensate for potential non response, the final total sample size was estimated to be 859. An updated list of all PHC centers was prepared, ten urban, six rural and two Hegar (35 and $60 \mathrm{Km}$ distance from $\mathrm{Al}$ Hassa respectively), $\mathrm{PHC}$ centers were randomly chosen from the list. Considering female to male ratio of attendees of 1.5:1 (Amin et al., 2011), an appropriate sampling fraction was used to estimate the required sample according to gender and residence distribution. All adult Saudis of both genders aged $\geq 50$ years attending the selected PHC centers during the period from October 1st 2014 to August 2nd 2015 were invited to participate through personal approach after receiving proper orientation. Of 1203 (592 women and 611 men) PHC centers attendees approached, 471 women and 476 men agreed to participate. Saudis attendees with difficulties in communications due to neurological/cognitive conditions were excluded.

\section{Data collection}

Participants who agreed to participate were invited to a personal interview employing a structured data collection form by two trained nurses (one male and one female) at each PHC center under the supervision of the investigators. The data collection form was designed to include the following information:

-Socio-demographics: age in years, gender, residence, family income and educational status.

-Personal information relevant to CRC: ever heard about CRC, colon cancer among family and relatives, ever examined (screened) for CRC, mean reasons for the examination (screening), methods used and age at examination (screening) and the previous diagnosis of having $\mathrm{CRC}$.

-Awareness about early signs/symptoms and risk factors of CRC: six questions with multiple choice options (true, false, and do not know) to assess their knowledge about the early signs and symptoms of CRC. Another 10 questions were used to assess their knowledge about the risk factors of CRC with the same close ended options. Questions used in this section were adopted from the available literature and the American Cancer Society (American Cancer Society, 2011; Zubaidi et al., 2015).

-Barriers to CRCS: close-ended questions about the possible barriers to CRCS with multiple option format (yes, no and not sure), these questions were adopted following the available literature (Berkowitz et al., 2008; Hoffman et al., 2011) and the results of the pilot testing. List of the possible barriers were prepared with instructions to the participants to choose all the possible barriers they perceived. 
Original data collection form was designed in English, translated by two experts into Arabic and back translated to English by another expert. The interview was conducted in Arabic at the end of each patient's PHC visit.

-Barriers to CRCS among Saudis from the providers' perspective were also assessed using a self-administered data collection form: General and family physicians at the selected PHC centers were targeted to collect the following information: age, qualifications, and duration of work at PHC centers. Ever received inquiries about CRC from attendees, ever recommend CRCS to patients and how frequently, and the possible barriers among Saudi patients to CRCS from their own perspectives. The data collection form was in English as many of the providers working in $\mathrm{Al}$ Hassa are expatriates and Arabic is not their native language. Of the assigned providers at the selected PHC centers $(n=56), 39$ agreed to participate (response rate of $69.6 \%$ ).

Pilot testing: The provisional data collection form was tested on 58 Saudis (within the same age range) attended for primary health services at a nearby primary center beyond the sample size with the following objectives:

-Training of the data collectors on conducting personal interviews.

-Clarity and comprehension of the terms and questions.

-Absence of ambiguity (if any).

-The perceived barriers were initially formulated and listed from the available literature; further addition of the possible barriers was considered after pilot testing.

-Reliability analysis was carried out: The overall internal consistency (Cronbach's alpha) of items of knowledge of early signs and symptoms (6 items) and risk factors (10 items) was 0.69 , more for the risk factors section (0.78) compared to knowledge about early signs and symptoms $(0.62)$.

\section{Data analysis}

Forms with missing of one or more items were discarded $(n=63) ; 884$ forms were eligible for final analysis. Data analysis was carried out using SPSS 21.0 (SPSS Inc, IBM, U.S.A.). For the awareness of early signs-symptoms (6 points) and risk factors (10 points): correct responses assigned one point while do not know or incorrect responses received nil. For the knowledge scores those attained $\geq 9$ points (out of 16 points, the 75 th percentile for the score) were assigned as being knowledgeable, while those who attained $<9$ points were assigned as being not knowledgeable. These cut-offs were employed for the generation of logistic regression analysis to determine the possible predictors (socio-demographics and other possible independent variables) of the dependent variables (knowledge of risk factors and early signs and symptoms of CRC). For categorical data, frequency, proportions and percentage were used for reporting, Chi square was used for comparison. For continuous data; mean, standard deviation, and median were used, t-test, Mann Whitney and Kruskall Wallis tests were used for comparison. Another logistic regression model was generated to determine possible predictors for screening (dependent variable) by inclusion of significant potential independent variables revealed at univariate analysis. $\mathrm{P}$ value of $\leq 0.05$ was considered significant.

Exploratory Factor Analysis: A principal components analysis with an orthogonal (Varimax) rotation was used to identify the factors underlying the different perceived barriers to the uptake of CRCS among the sampled Saudis aged $\geq 50$ years. Eigenvalue of 1.0 was used for factor inclusion with examination of scree plots to confirm appropriate number of possible factors. The criteria used for item elimination to maintain simple structure included were the primary factor loading below $0.4 \mathrm{and} /$ or the presence of cross-loading (Kim and Muller, 1978).

Following the process of items elimination, the remaining items were included in the factor analysis with examination of their loadings. The retained factors were assessed for reliability using Cronbach's alpha as a measure of internal consistency (Cronbach, 1951). The factorability of the 15 barriers was examined at the outset of the analysis. Criteria (Hair et al., 1998) employed to determine the factorability of the correlation included: the result of the intercorrelation matrix which showed that 12 (out of 15 items) were correlated (correlation coefficient $\mathrm{r}=0.30$ with at least one item) suggested reasonable factorability. In addition to the Kaiser-Meyer-Olkin measure of sampling adequacy (0.691) which was above the commonly recommended value of 0.6 , with significant the Bartlett's test of Sphericity (Chi square $=1000.03$, $\mathrm{P}=0.001$ ), confirming that each item shared some common variance with other items. Based on the above indicators, principal component analysis was warranted suitable for these 12 items.

\section{Ethical considerations}

Permissions were obtained from the local Health Authorities and our institution. Participants were provided with full explanation of the study with the emphasis on their right of not to participate. Informed consent forms were obtained from the PHC centers attendees and health care providers and data confidentiality was maintained all through.

\section{Results}

Out of a total of 947 questionnaires, 884 were fully completed and included in the analysis. Sociodemographic characteristics and previous CRCS of the study participants were shown in Table 1 . The study sample consisted of 464 males and 420 females, with a mean age of $56.1 \pm 6.2$ years. Nearly half of the study participants $(48.4 \%)$ lived in the urban region of Al Hassa Governorate. The majority $(82.5 \%)$ had secondary school education and less. About $77 \%$ of the respondents heard about CRC, $12.8 \%$ mentioned having relatives with the disease, and only $8.6 \%$ reported prior screening. Among the previously screened individuals $(n=76)$, regular checkup (28.9\%); bloody diarrhea (19.7\%); prolonged chronic constipation $(11.8 \%)$; and abdominal pains (10.5\%) represented the most frequent causes for screening. Endoscopy was the most common method for screening (72.4\%) followed by occult fecal blood test (61.8\%). Only 4 cases were previously diagnosed with CRC.

Knowledge of the study participants about early 
symptoms/signs and risk factors of CRC showed that, blood in stool and changes in bowel habits were correctly identified by $54.2 \%$ and $48 \%$ of the study participants respectively, as symptoms for CRC. However, only about a quarter of the respondents correctly identified abdominal cramping pain $(26.8 \%)$ and unexplainable weakness (23.5\%) as symptoms of CRC and also knew that CRC doesn't present early with abdominal mass (24.7\%). Moreover, more than one-third of the study participants $(36.3 \%)$ identified unintended weight loss as one of the symptoms of CRC. The mean total knowledge score for signs and symptoms was $2.1 \pm 1.8$ (median=2, IQR: $0-4$ ) (Table 2).

Knowledge about risk factors of CRC revealed that; about one-fifth only (20.8\%) of the respondents correctly knew that CRC isn't more common in men and that positive family history is a risk factor (19.3\%). Moreover,

Table 1. Socio-demographics, previous screening for colo-rectal cancer of the included participants $(n=884)$.

\begin{tabular}{|c|c|c|}
\hline $\begin{array}{l}\text { Socio-demographic and CRC } \\
\text { screening variables }\end{array}$ & Number & $\%$ \\
\hline - Age in years: mean \pm SD & $56.1 \pm 6.2$ & \\
\hline \multicolumn{3}{|l|}{-Age categories: } \\
\hline $50-<60$ years & 676 & 76.4 \\
\hline $60-<70$ years & 160 & 18.2 \\
\hline 70 or more & 48 & 5.4 \\
\hline \multicolumn{3}{|l|}{-Gender: } \\
\hline Males & 464 & 52.5 \\
\hline Females & 420 & 47.5 \\
\hline \multicolumn{3}{|l|}{-Residence: } \\
\hline Urban & 428 & 48.4 \\
\hline Rural & 284 & 32.1 \\
\hline Hegra* (Bedouins) & 172 & 19.5 \\
\hline \multicolumn{3}{|l|}{-Educational status: } \\
\hline Illiterate & 188 & 21.3 \\
\hline Primary-preparatory & 265 & 30 \\
\hline Secondary & 276 & 31.2 \\
\hline College or higher & 155 & 17.5 \\
\hline -Ever heard about CRC** & 679 & 76.8 \\
\hline -Relatives with CRC & 113 & 12.8 \\
\hline -Ever screened for CRC & 76 & 8.6 \\
\hline \multicolumn{3}{|l|}{$\begin{array}{l}\text {-Main Reasons for screening } \\
(n=76) \text { : }\end{array}$} \\
\hline -Regular check-up & 22 & 28.9 \\
\hline -Bloody diarrhea/rectal bleeding & 15 & 19.7 \\
\hline $\begin{array}{l}\text {-Abdominal pains/pain with defeca- } \\
\text { tion }\end{array}$ & 8 & 10.5 \\
\hline -Irritable bowel syndrome & 4 & 5.3 \\
\hline -Prolonged chronic constipation & 9 & 11.8 \\
\hline -Prolonged diarrhea with mucus & 3 & 3.9 \\
\hline -Colonic inflammation & 2 & 2.6 \\
\hline \multicolumn{3}{|c|}{-Age at screening: ( 8 cases were screened twice or more) } \\
\hline$<40$ years & 9 & 11.8 \\
\hline $40-<50$ years & 21 & 27.6 \\
\hline $50-<60$ years & 46 & 60.5 \\
\hline$\geq 60$ years & 12 & 15.8 \\
\hline \multicolumn{3}{|c|}{-Methods used for screening: (not mutually exclusive) } \\
\hline -Endoscopy & 55 & 72.4 \\
\hline -Occult fecal blood test & 47 & 61.8 \\
\hline -Others! & 44 & 57.9 \\
\hline $\begin{array}{l}\text {-Cases previously diagnosed with } \\
\text { CRC }(n=884)\end{array}$ & 4 & 0.5 \\
\hline
\end{tabular}

! includes CT, barium contrast imaging. colonic polyps and type 2 diabetes were correctly identified by only $12 \%$ and $14 \%$ of participants respectively, as risk factors for CRC. However, $40 \%$ knew that CRC occurs more after the age of 50 years. About two and one for every three respondents $(61.5 \%$ and $34.6 \%$, respectively) correctly knew that smoking and obesity are risk factors. Nearly a quarter of respondents knew that physical inactivity (27.6\%), excessive intake of red meat $(26.2 \%)$ and fewer intakes of fruits and vegetables $(27.3 \%)$ are among the risk factors for colon cancer. The mean total knowledge score for risk factors was 3.2 \pm 2.6 (median=3, IQR: 1-5). Total knowledge scores were assigned 16 points, $66.4 \%$ of participants were considered not knowledgeable (scored $<9$ out of 16 points).

Analysis of data revealed that those aged 50- $<60$ years scored significantly higher for both the signs/symptoms $(\mathrm{P}=0.015)$ and risk factors scores $(\mathrm{P}=0.028)$. Also, college

Table 2. Awareness of the included participants about early signs and symptoms and risk factors for colorectal cancer $(n=884)$

\begin{tabular}{|c|c|c|}
\hline \multirow{2}{*}{ Items } & \multicolumn{2}{|c|}{ Correct responses } \\
\hline & Number & $\%$ \\
\hline \multicolumn{3}{|l|}{$\begin{array}{l}\text { Early signs and symptoms of colo- } \\
\text { rectal cancer: }\end{array}$} \\
\hline $\begin{array}{l}\text { 1- Changes and alterations in the } \\
\text { bowel habits (diarrhea-constipation, } \\
\text { last for many days): True }\end{array}$ & 424 & 48 \\
\hline $\begin{array}{l}\text { 2- Blood in stool or dark colored } \\
\text { stool: True }\end{array}$ & 479 & 54.2 \\
\hline $\begin{array}{l}\text { 3- Abdominal cramping (belly) pain: } \\
\text { True }\end{array}$ & 237 & 26.8 \\
\hline $\begin{array}{l}\text { 4- Early presenting with abdominal } \\
\text { mass: False }\end{array}$ & 218 & 24.7 \\
\hline 5- Unintended weight loss: True & 321 & 36.3 \\
\hline $\begin{array}{l}\text { 6- Unexplainable weakness and } \\
\text { fatigue: True }\end{array}$ & 208 & 23.5 \\
\hline $\begin{array}{l}\text { Cronbach's alpha for internal } \\
\text { consistency: }\end{array}$ & 0.741 & \\
\hline \multicolumn{3}{|l|}{ Total score: (out of 6 points) } \\
\hline Mean \pm SD & $2.1 \pm 1.8$ & \\
\hline Median (Interquartile range) & $2.0(0.0-4.0)$ & \\
\hline \multicolumn{3}{|l|}{ Risk factors of colo-rectal cancer: } \\
\hline 1- More in men: False & 184 & 20.8 \\
\hline 2- More after 50 years of age: True & 355 & 40.1 \\
\hline $\begin{array}{l}\text { 3- More among those with positive } \\
\text { family history: True }\end{array}$ & 171 & 19.3 \\
\hline $\begin{array}{l}\text { 4- More among those with colonic } \\
\text { polyps or ulcerative colitis: True }\end{array}$ & 105 & 11.9 \\
\hline 5- Smoking incre & 544 & 61.5 \\
\hline 6- Obesity increases the risk: True & 306 & 34.6 \\
\hline $\begin{array}{l}\text { 7- Physical inactivity increases the } \\
\text { risk: True }\end{array}$ & 244 & 27.6 \\
\hline $\begin{array}{l}\text { 8- Excessive intake of red meat } \\
\text { increases the risk: True }\end{array}$ & 232 & 26.2 \\
\hline $\begin{array}{l}\text { 9- Less intake of fruits and vegetables } \\
\text { increases the risk: True }\end{array}$ & 241 & 27.3 \\
\hline $\begin{array}{l}\text { 10- Type } 2 \text { diabetes mellitus increases } \\
\text { the risk: True }\end{array}$ & 124 & 14 \\
\hline $\begin{array}{l}\text { Cronbach's alpha for internal } \\
\text { consistency: }\end{array}$ & 0.733 & \\
\hline re: (out of 10 points) & & \\
\hline Mean \pm SD & $3.2 \pm 2.6$ & \\
\hline Median (Interquartile range) & $3.0(1.0-5$. & \\
\hline
\end{tabular}


Colon Cancer among Older Saudis: Awareness of Risk Factors, Early Signs, and Perceived Barriers to Screening

education or higher was significantly associated with increased both scores $(\mathrm{P}=0.001)$. Those who recalled hearing information about $\mathrm{CRC}$ or had relatives with the disease had a significantly higher awareness of signs, symptoms and risk factors. Prior CRCS had positive influence on the awareness of study participants about the risk factors $(\mathrm{P}=0.029)$ (Table 3$)$.

The logistic regression model identified the possible

Table 3. Awareness about Early Signs and Symptoms and risk Factors of Colo-Rectal Cancer in Relation to Participants' Characteristics

\begin{tabular}{|c|c|c|c|c|}
\hline \multirow{2}{*}{ Variables } & \multicolumn{2}{|c|}{ Signs and symptoms score } & \multicolumn{2}{|c|}{ Risk factors score } \\
\hline & Mean \pm SD & $\mathrm{P}$ value & Mean \pm SD & $\mathrm{P}$ value \\
\hline \multicolumn{5}{|l|}{ Age categories: } \\
\hline $50-<60$ years & $2.2 \pm 1.9$ & & $4.3 \pm 2.6$ & \\
\hline $60-<70$ years & $2.0 \pm 1.8$ & & $3.9 \pm 2.6$ & \\
\hline 70 or more & $1.5 \pm 1.8$ & $0.015^{*}$ & $2.5 \pm 2.5$ & $0.028 *$ \\
\hline \multicolumn{5}{|l|}{ Gender: } \\
\hline Males & $2.1 \pm 1.9$ & & $3.1 \pm 2.7$ & \\
\hline Females & $2.2 \pm 1.8$ & $0.439 * *$ & $3.3 \pm 2.5$ & $0.157 * *$ \\
\hline \multicolumn{5}{|l|}{ Residence: } \\
\hline Urban & $2.1 \pm 1.9$ & & $3.2 \pm 2.6$ & \\
\hline Rural & $2.2 \pm 1.8$ & & $3.4 \pm 2.6$ & \\
\hline Hegra* (Bedouins) & $2.1 \pm 1.9$ & $0.881 *$ & $2.9 \pm 2.7$ & $0.147 *$ \\
\hline \multicolumn{5}{|l|}{ Educational status: } \\
\hline Illiterate & $1.3 \pm 1.7$ & & $3.4 \pm 2.4$ & \\
\hline Primary-preparatory & $1.8 \pm 1.8$ & & $3.0 \pm 2.7$ & \\
\hline Secondary & $2.2 \pm 1.8$ & & $3.2 \pm 2.5$ & \\
\hline College or higher & $2.5 \pm 1.9$ & $0.001 *$ & $4.7 \pm 2.6$ & $0.001 *$ \\
\hline \multicolumn{5}{|l|}{ Ever heard about $\mathrm{CRC}^{* * *}$} \\
\hline Yes & $2.5 \pm 1.8$ & & $4.6 \pm 2.5$ & \\
\hline No & $1.1 \pm 1.5$ & $0.001 * *$ & $2.8 \pm 2.5$ & $0.001 * *$ \\
\hline \multicolumn{5}{|l|}{ Relatives with CRC } \\
\hline Yes & $2.8 \pm 1.8$ & & $3.9 \pm 2.6$ & \\
\hline No & $2.1 \pm 1.8$ & $0.010 * *$ & $3.1 \pm 2.6$ & $0.001 * *$ \\
\hline \multicolumn{5}{|l|}{ Ever screened for CRC } \\
\hline Yes & $2.1 \pm 2.0$ & & $3.9 \pm 2.6$ & \\
\hline Never & $2.1 \pm 1.8$ & $0.785 * *$ & $3.1 \pm 2.6$ & $0.029 * *$ \\
\hline
\end{tabular}

$\mathrm{CRC}=$ colo-rectal cancer, $\mathrm{SD}=$ standard deviation, ${ }^{*}$ Kruskal Wallis test, $* *$ Mann Whitney test.

Table 4. Possible Predictors Using Logistic Regression Model for Colo-Rectal Cancer Screening and Awareness About Signs and risk factors among Participants

\begin{tabular}{|c|c|c|c|c|c|c|}
\hline \multirow{2}{*}{$\begin{array}{c}\text { Independent } \\
\text { variables }\end{array}$} & \multicolumn{3}{|c|}{ Colo-rectal cancer screening predictors } & \multicolumn{3}{|c|}{$\begin{array}{c}\text { Knowledge predictors (high knowledge scores }= \\
\qquad 9 \text { points) }\end{array}$} \\
\hline & B coefficient & P value & Odds ratio (95\% C.I) & B coefficient & P value & Odds ratio $(95 \%$ C.I) \\
\hline Gender: females & -1.269 & 0.001 & $0.28(0.14-0.57)$ & 0.212 & 0.203 & $1.24(0.89-1.71)$ \\
\hline $\begin{array}{l}\text { Age groups (years): } \\
50-<60\end{array}$ & & & 1 & & & 1 \\
\hline $60-<70$ & 1.485 & 0.045 & $4.42(1.37-14.32)$ & 0.035 & 0.928 & $1.04(0.49-2.12)$ \\
\hline$\geq 70$ & 0.754 & 0.114 & $3.51(0.94-12.11)$ & -0.212 & 0.607 & $0.81(0.36-1.81)$ \\
\hline $\begin{array}{l}\text { Marital status: } \\
\text { widowed/divorced/ } \\
\text { single }\end{array}$ & -2.234 & 0.001 & $0.11(0.10-0.23)$ & 0.09 & 0.706 & $1.09(0.69-1.74)$ \\
\hline $\begin{array}{l}\text { Education: } \\
<\text { college education }\end{array}$ & -1.012 & 0.015 & $0.36(0.16-0.82)$ & -0.43 & 0.037 & $0.65(0.43-0.97)$ \\
\hline Residence: Urban & & & 1 & & & 1 \\
\hline Hegara (Bedouin) & 0.426 & 0.163 & $1.53(0.84-2.79)$ & -0.321 & 0.06 & $0.73(0.52-1.01)$ \\
\hline Rural & -0.56 & 0.245 & $0.57(0.22-1.70)$ & -0.173 & 0.434 & $0.84(0.55-1.29)$ \\
\hline $\begin{array}{l}\text { Ever heard about } \\
\text { CRC: Never }\end{array}$ & -0.461 & 0.22 & $0.63(0.31-1.32)$ & -- & -- & --- \\
\hline $\begin{array}{l}\text { Relatives with } \\
\text { CRC: None }\end{array}$ & -1.192 & 0.001 & $0.30(0.17-0.56)$ & -0.393 & 0.07 & $0.68(0.44-1.03)$ \\
\hline $\begin{array}{l}\text { Screened for CRC: } \\
\text { Never }\end{array}$ & -- & -- & --- & -0.347 & 0.243 & $0.71(0.39-1.27)$ \\
\hline $\begin{array}{l}\text { Percent predicted } \\
\text { for the model }\end{array}$ & 92.5 & & & 67.8 & & \\
\hline $\begin{array}{l}\text { Hosmer-Lemeshow: } \\
\text { Chi square (P value) }\end{array}$ & $11.43(0.179)$ & & & $2.97(0.936)$ & & \\
\hline
\end{tabular}


Table 5. Perceived Barriers to Colo-Rectal Cancer Screening by the Included Saudi Participants in Relation to Gender

\begin{tabular}{|c|c|c|c|c|}
\hline \multirow{2}{*}{ Perceived barriers* } & \multicolumn{4}{|c|}{ Gender: No. (\%) } \\
\hline & $\operatorname{Men}(n=464)$ & Women $(n=420)$ & Total $(n=884)$ & $\mathrm{P}$ value** \\
\hline 1- Fear of results & $179(38.6)$ & $214(50.9)$ & $393(44.5)$ & 0.001 \\
\hline 2- Fear of painful procedures & $161(34.7)$ & 176(41.9) & $337(38.1)$ & 0.041 \\
\hline 3- Shyness & $109(23.5)$ & $216(51.4)$ & $325(36.8)$ & 0.001 \\
\hline 4- Lack of time & $259(55.8)$ & $184(43.8)$ & $443(50.1)$ & 0.001 \\
\hline 5- Previous bad experience with screening & $79(17.0)$ & $75(17.9)$ & 154(17.4) & 0.84 \\
\hline 6- Absence of signs and symptoms & $261(56.3)$ & $191(45.5)$ & $452(51.1)$ & 0.006 \\
\hline 7- Lack of awareness about symptoms and signs & $143(30.8)$ & $131(31.2)$ & $274(31.0)$ & 0.905 \\
\hline 8- Feeling unrest in dealing with doctors & $94(20.3)$ & $102(24.3)$ & $196(22.2)$ & 0.15 \\
\hline 9-Lack of knowledge about the tests & $121(26.1)$ & $118(28.1)$ & $239(27.0)$ & 0.5 \\
\hline 10- Lack of specialized facilities & $99(21.3)$ & $109(26.0)$ & $208(23.5)$ & 0.106 \\
\hline 11- Lack of transportation & $19(4.1)$ & $29(6.9)$ & $48(5.4)$ & 0.058 \\
\hline 12- Lack of public awareness CRC screening program & $358(77.2)$ & $249(59.3)$ & $607(68.7)$ & 0.001 \\
\hline $\begin{array}{l}\text { 13- Lack of providers' knowledge about the recommended } \\
\text { screening for CRC }\end{array}$ & $327(70.5)$ & $268(63.8)$ & $595(67.3)$ & 0.006 \\
\hline 14- Health care providers are not trustworthy & $136(29.3)$ & $249(59.3)$ & $320(36.2)$ & 0.001 \\
\hline 15- Financial burden and cost of screening & $85(18.3)$ & $48(11.4)$ & $133(15.0)$ & 0.003 \\
\hline
\end{tabular}

*Not mutually exclusive $* *$ Chi square for independence. $* *$ Chi square for independence

Table 6. Summary of Items And Factor Loadings of Three Factor Solution for Barriers to Colo-Rectal Cancer screening.

\begin{tabular}{|c|c|c|c|c|}
\hline \multirow{3}{*}{ Perceived barriers* } & \multicolumn{3}{|c|}{ Components $* *$} & \multirow{3}{*}{ Communality } \\
\hline & 1 & 2 & 3 & \\
\hline & Personal fears & Lack of knowledge & Health care related & \\
\hline Fear of results & 0.831 & & & 0.738 \\
\hline Shyness & 0.83 & & & 0.753 \\
\hline Fear of pains & 0.772 & & & 0.74 \\
\hline Lack of confidence in physician & 0.485 & & & 0.468 \\
\hline Lack of health education and awareness & & 0.807 & & 0.771 \\
\hline $\begin{array}{l}\text { Lack of providers' knowledge about the } \\
\text { recommended screening }\end{array}$ & & 0.726 & & 0.764 \\
\hline Lack of CRC symptoms & & 0.56 & & 0.48 \\
\hline Previous bad experience of screening & & & 0.72 & 0.598 \\
\hline Financial problems & & & 0.651 & 0.449 \\
\hline Busy & & & 0.532 & 0.435 \\
\hline Eignevalue & 2.951 & 2.132 & 1.616 & \\
\hline Cronbach's alpha & 0.764 & 0.611 & 0.522 & \\
\hline$\%$ variance explained & 34.8 & 23.7 & 19.1 & \\
\hline
\end{tabular}

*Not mutually exclusive; ** Principal component analysis using Varimax with Kaiser Normaization, Kaiser-Meyer-Olkin for sample adequacy $=0.691$, Bartlett's test for sphericity, Chi=1000.03, $\mathrm{P}=0.001$.

predictors for CRCS and those for knowledge about signs, symptoms, and risk factors as follows (Table 4): female participants $(\mathrm{OR}=0.28 ; 95 \% \mathrm{CI}=0.14-0.57 ; \mathrm{P}=0.001)$, unmarried $(\mathrm{OR}=0.11 ; 95 \% \mathrm{CI}=0.10-0.23 ; \mathrm{P}=0.001)$, having less than college education $(\mathrm{OR}=0.36 ; 95 \%$ $\mathrm{CI}=0.16-0.82 ; \mathrm{P}=0.015)$, and with no relatives with $\mathrm{CRC}$ ( $\mathrm{OR}=0.30 ; 95 \% \mathrm{CI}=0.17-0.56 ; \mathrm{P}=0.001$ ), had lower odds of being screened for CRC. Also participants aged 60 to $<70$ years had higher odds of being screened $(\mathrm{OR}=4.42$; $95 \% \mathrm{CI}=1.37-14.32 ; \mathrm{P}=0.045)$. Having less than college education was found to be a negative predictor for knowledge about CRC (OR=0.65; 95\% CI=0.43-0.97; $\mathrm{P}=0.037$ ).

There was a significant difference between men and women in relation to the stated perceived personal barriers to CRCS (Table 5). Fears of the results of screening was significantly higher among women compared to men (50.9\% vs. $38.6 \%, \mathrm{P}=0.001)$, fear of painful procedures (41.9\% vs. $34.7 \%, \mathrm{P}=0.041)$, and shyness $(51.4 \%$ vs. $23.5 \%, \mathrm{P}=0.001)$ were also more commonly stated barriers by women rather than men. More women thought that health care providers are not trustworthy $(59.3 \% \mathrm{vs}$. $29.3 \%, \mathrm{P}=0.001)$. More men reported lack of time $(55.8 \%$ vs. $43.8 \%, \mathrm{P}=0.001)$, absence of symptoms and signs (56.3\% vs. $45.5 \%, \mathrm{P}=0.006)$, and cost of screening $(18.3 \%$ vs. $11.4 \%, \mathrm{P}=0.003)$. Moreover, a significantly higher percent of men thought that lack of public awareness about CRCS program $(77.2 \%$ vs. $59.3 \%, \mathrm{P}=0.001)$ and lack of providers knowledge about the recommended screening for the disease $(70.5 \% v s .63 .8 \%, \mathrm{P}=0.006)$, are barriers. About $4 \%$ and $7 \%$ of men and women respectively, cited lack of transportation as a barrier $(\mathrm{P}=0.058)$.

Exploratory factor analysis: the three components model explained $77.6 \%$ of the variation in the perceived barriers towards CRCS in the studied group. A predefined barrier was considered as being loaded on a specific component when its absolute factor loading was $<4$.

Exploratory factor analysis with three factors solution showed that personal fears (especially fears of the screening results and shyness) was the major factor that 
Table 7. Barriers to Colo-Rectal Cancer Screening Viewed by Primary Health Care Physicians (n=39)

\begin{tabular}{lccccc}
\hline \multirow{2}{*}{ Barriers } & \multicolumn{5}{c}{ Responses: no. (\%) } \\
\cline { 2 - 6 } & Strongly agree & Agree & Not sure & Disagree & Strongly disagree \\
\hline 1- Lack of physicians' knowledge about CRC & $7(17.9)$ & $11(28.2)$ & $9(23.1)$ & $7(17.9)$ & $5(12.8)$ \\
screening & $2(5.1)$ & $8(20.5)$ & $13(33.3)$ & $6(15.4)$ & $10(25.6)$ \\
2-Lack of trust in providers & $5(12.8)$ & $14(35.9)$ & $7(17.9)$ & $9(23.1)$ & $4(10.3)$ \\
3- patients' fears of screening results & $11(28.2)$ & $10(25.6)$ & $8(20.5)$ & $5(12.8)$ & $5(12.8)$ \\
4-Fears of the painful screening procedures & $5(12.8)$ & $11(28.2)$ & $7(17.9)$ & $6(15.4)$ & $5(12.8)$ \\
5- Shyness to be screened & $2(5.1)$ & $7(17.9)$ & $10(25.6)$ & $11(28.2)$ & $9(23.1)$ \\
6- Time constraint & $15(38.5)$ & $12(30.8)$ & $7(17.9)$ & $4(10.3)$ & $1(2.6)$ \\
7- Lack of symptoms and signs & $18(46.2)$ & $12(30.8)$ & $7(17.9)$ & $1(2.6)$ & $1(2.6)$ \\
8- Lack of public awareness about CRC screening & 0 & $3(7.7)$ & $6(15.4)$ & $17(43.6)$ & $13(33.3)$ \\
9- Financial problem & $10(25.6)$ & $17(43.6)$ & $6(15.4)$ & $4(10.3)$ & $2(5.1)$ \\
10- Lack of specialized centers for CRC & \multicolumn{5}{c}{} \\
\hline
\end{tabular}

hinder CRCS with high loading eigenvalue of 2.951, explaining $34.8 \%$ of the barriers of the included sample toward utilization of CRCS. The second factor with high eigenvalue of 2.132 , and explaining $23.7 \%$ of the barriers to CRCS was related to lack awareness, including items related to lack of health education and awareness about CRC, providers' insufficient knowledge about screening, and the absence of signs and symptoms of CRC (perceiving of early signs and symptoms stemmed out of the prior knowledge), the third factor included personal and health related items mainly previous bad experience with screening (not essentially for CRC) (Table 6).

Barriers to CRCS from the PHC physicians' perspectives were shown in Table 7. About $28 \%$ agreed that lack of physicians' knowledge about CRCS was a barrier, while $33.3 \%$ were not sure if lack of trust in providers was a problem. Patients' fears of screening results and shyness were among the barriers as agreed by nearly $36 \%$ and $28 \%$ of physicians respectively; while fears of painful screening procedures were strongly agreed by $28.2 \%$. Nearly one-fourth of them $(25.6 \%)$ was not sure if time constraint was a barrier. However, a higher percent of physicians strongly agreed that lack of public awareness about CRCS (46.2\%) and lack of symptoms and signs $(38.5 \%)$ were among the barriers. More than $40 \%$ of physicians disagreed that financial problems hinder CRCS, but agreed that lack of specialized centers for CRC was responsible for low screening uptake.

\section{Discussion}

The findings of the current study will be crucial for policy makers and health care practitioners in Saudi Arabia as it looked at the current knowledge of Saudis regarding symptoms, signs, risk factors of CRC and barriers to screening. Also, it assessed CRCS barriers from the PHC physicians' perspectives. This cross sectional study revealed a low level of knowledge about the symptoms/ signs, risk factors and opportunistic screening behavior for CRC among older Saudis from Al Hassa region. Personal fears were the leading factor that explained more than $30 \%$ of low uptake of screening and together with the lack of awareness constituted close to $60 \%$ of barriers that hinder them from utilizing the CRCS.

Worldwide, a considerable body of evidence highlighted low levels of knowledge about CRC in many countries. The Asia Pacific Working Group in Colorectal Cancer conducted a multinational survey in various Asia Pacific regions and detected low knowledge scores for symptoms and risk factors, with quite a number of regions scoring 0 (Koo et al., 2012). Evaluation of results in the current study revealed poor levels of knowledge among the respondents as there were large knowledge gaps towards many individual items; about two-thirds $(66.4 \%)$ were considered not knowledgeable about CRC. Only slightly more than one-third of participants identified unintentional weight loss as a symptom of CRC. Moreover, about one-fourth knew that CRC doesn't present early with an abdominal mass and identified abdominal cramping pain and unexplainable weakness as symptoms of CRC. Regarding risk factors of CRC, nearly one-fifth only knew that CRC isn't more common in men and that family history is a risk factor. Another important finding regarding the same concept was that just about one-third knew that obesity is a risk factor. Nearly a quarter of respondents identified physical inactivity, excessive intake of red meat and fewer intakes of vegetables and fruits as risk factors. These findings could be attributed to lack of dissemination of information about CRC in Saudi Arabia which reflects the need for implementation of health education and public awareness programs.

Similarly, low levels of knowledge about CRC have been reported by other studies (Ravichandran et al., 2011; Puteh et al., 2014).For example, in another study conducted in Saudi Arabia, a general lack of knowledge has been identified about CRC risk factors and screening tools. In that study, only one-third of respondents were able to correctly define CRC and less than one-fifth (18\%) correctly identified colorectal polyps and red meat as risk factors (Al Wutayd et al., 2015). In a study conducted in Italy, physical inactivity and polyps were identified by $24 \%$ and $63 \%$ respectively as risk factors (Sessa et al., 2008). Public awareness of CRC was also low in Ireland, which has stressed the importance of development of a national screening program (McVeigh et al., 2013).

In the current study, respondents between the age of 50-59 years and those with higher education had a significantly higher knowledge scores (symptoms/ signs and risk factors). Having relatives with CRC was significantly associated with increased both knowledge scores, however, prior CRCS was associated with a significantly higher knowledge score as regards risk factors 
only. Readiness to undergo screening is affected by the individual's perceived susceptibility, perceived benefits and barriers, and clues to take action. Consequently, the positive influence of having family members with CRC could be explained by the motivation it provides to undertake a healthy behavior such as screening(Sung et al., 2008). Similarly, higher education levels and family history of CRC were among the factors that affected the knowledge of CRC in another another study conducted in Saudi Arabia (Al Wutayd et al., 2015). These findings were also in agreement with several previous studies carried out to identify the factors influencing knowledge of CRC (Aparna, 2014; Puteh et al., 2014).

There was no significant difference between gender and knowledge scores in this study. In contrast, male respondents were more likely to answer correctly as reported by other studies in Saudi Arabia (Ravichandran et al., 2011; Mosli and Al-Ahwal, 2012). Females had higher levels of knowledge about CRC in a study conducted in the United States (Aparna, 2014).

In this study, rates of reported CRCS were low (8.6\%). Similar low rates were identified in a study conducted in Iran, where only $4.2 \%$ of respondents reported prior CRCS screening (Bidouei et al., 2014). In contrast, higher rates $(45 \%)$ were reported in a study conducted in North Carolina to examine perceptions of barriers and benefits to CRCS among African-Americans (James et al., 2002).

After conducting a logistic regression model, it was noticed that female gender, being unmarried, lower levels of education and having no relatives with CRC were significantly associated with a lower CRCS uptake. Married people have been found to be more compliant with healthier behavior and more willing to take part in screening programs (Van Jaarsveld et al., 2006). Predictors of CRCS, in a study conducted in Canada (Singh et al., 2015), included higher education, higher income and not being a current smoker, while being unmarried, being obese, feeling well were associated with decreased chance of CRCS. Moreover, in a study conducted by MQueen et al. (2007), significant variables for CRCS after multivariate analysis included both demographic variables (older age, higher level of education, family history of CRC or polyps) and psychosocial variables (self-efficacy, support for CRCS from family members, and strong intention to be screened). Christy et al. (2013) conducted a multivariate logistic regression analysis to identify predictor variables for promoting CRCS. It was concluded that participants who were older $(\mathrm{P}=0.003)$ and were married $(\mathrm{P}=0.045)$ had lower odds of having a discussion about colon tests with their PCPs, however, they had higher odds of having such a discussion if they had a family member who encouraged CRCS $(\mathrm{P}=0.002)$.

In the present study, having lower levels of education was identified by logistic regression analysis as a negative predictor for knowledge about CRC symptoms and risk factors $(\mathrm{P}=0.037)$. In agreement with other studies, the most educated populace knew more about CRC signs, risk factors and screening tools (Miller et al., 2007; Zubaidi et al., 2015). These findings reflect the importance of conducting educational programs about CRC.

There was a significant difference between most of the perceived barriers to CRCS and gender in the current study. More women reported fear of results, fear of painful procedures, shyness and lack of transportation as barriers. However, absence of signs and symptoms, lack of public awareness about CRCS programs, lack of providers' knowledge about the recommended screening test, and costs of screening were more frequently cited by men. Similar findings were reported by Wong et al. (2013) who applied a Health Belief Model to identify genderspecific predictors of CRCS in an Asian population. Fears about discovering the disease, fears of colonoscopy, embarrassment and perception of colonoscopy as dangerous were cited by a significantly higher proportion of females than males as barriers to CRCS. More women were also more likely to perceive inconvenience in seeing a physician for CRCS as a barrier.

A wide range of qualitative studies have focused on views about the perceived barriers to CRC screening (Jones et al., 2010a; James et al., 2011). In this study, factor analysis was used to derive the barriers to CRCS among Saudi adults, three major barriers were identified; personal fears (loaded on fear of results, shyness, fear of pains, and lack of confidence in physicians), lack of knowledge (loaded on lack of awareness, lack of the provided knowledge about the recommended screening, and lack of CRC symptoms); and health-care related (loaded on previous bad experience with screening, financial problems and lack of time). Similar findings were obtained from a study which used focus group discussions to identify barriers to CRCS, nine domains were identified for which lack of awareness was the common factor e.g. unawareness of the prevalence of CRC, unawareness of the benefits and harms of CRCS, unawareness of the pros and cons of each test. Also, six domains were cited for fear e.g. fears of discovering the disease, fears of an invasive procedure, and fears of causing burden to the family. Time was also reported as a barrier in that study e.g. time needed for testing (e.g. missing work), and also time for building motivation to undergo screening, study options, and arrange testing. However, bad experience with previous CRCS tests was rarely reported (Jones et al., 2010a).

Other studies have shown that having no symptoms and the perception of good health accompanied by failure of physicians' recommendation were the most cited reasons for low screening uptake (Wee et al., 2005; Jones et al., 2010b; Bidouei et al., 2014). A low socioeconomic status (income, unemployment, educational level, and residence) has been associated with lower rates of screening uptake in many studies (Hay et al., 2003; Sun et al., 2004).

In this study, the most frequently perceived barriers to CRCS as "strongly agreed" from the physicians' perspectives were patient-related: lack of public awareness about CRCS, lack of symptoms and signs, and fear of painful procedures, whereas lack of specialized centers and lack of physicians' knowledge about CRCS were less frequently reported. Similarly, in another study conducted by Hoffman et al. (2011), physicians and adults in the general population had markedly different perspectives on barriers to CRCS. Physicians most frequently cited patient factors as being barriers, including fear of pain, 
shyness and anxiety, lack of insurance, and lack of knowledge about cancer and screening, while respondents were much more likely to report that lack of physicians' recommendations or lack of symptoms discouraged them for being screened. Furthermore, in a study conducted in Saudi Arabia to identify barriers to CRCS among family physicians, lack of patients' awareness was the most cited barrier (Demyati, 2014).

In conclusion, Poor levels of knowledge towards CRC symptoms and risk factors were detected among older ( $\geq 50$ years) Saudis attending PHC centers in Al Hassa region, Saudi Arabia. Female gender, being unmarried, with lower levels of education, and having no relatives with CRC were significantly associated with a lower CRCS uptake. Low educational level was identified as a negative predictor for knowledge about CRC. Perceived barriers to screening should be addressed before launching and implementing CRC screening programs concurrently with the initiation of health education campaigns targeting adults Saudis to increase public awareness.

\section{Acknowledgements}

The authors are grateful to the health authorities at the PHC centers in Al Hassa Governorate for their permission to carry out this study. The authors are thankful for all the participants who agreed to participate in the study.

\section{References}

Al Wutayd O, Alamri F, Ali A, et al (2015). Colorectal cancer risk factors: a study of knowledge, attitude and practice among adults in Riyadh, Saudi Arabia. Cancer Res, 3, 94-9.

Al-Eid H (2014). Cancer Incidence Report 2010, in Saudi Cancer Registry, Bazarbashi S, Editor. Ministry of Health: Kingdom Saudi Arabia. Accessed at http://www.chs.gov.sa/ $\mathrm{Ar} /$ mediacenter/ NewsLetter/2010\%20Report\%20(1).pdf.

Al-Eid HS and Al-Zahrani A. Cancer Incidence and Survival Report 2007, in Saudi Cancer Registry. Ministry of Health: Kingdom Saudi Arabia. Accessed at http://www.chs.gov.sa/ $\mathrm{Ar} /$ HealthRecords/CancerRegistry/CancerRegistryReports/ Incidence\% 20Report\% 202007. pdf.

American Cancer Society (2011). Colorectal cancer facts and figures 2011-2013. Atlanta: American cancer Society, 2011. Accessed at http://www.cancer.org/acs/groups/ content/@ epidemiologysurveilance/documents/document/ acspc-028312.pdf.

Amersi F, Agustin M, Ko CY (2005). Colorectal cancer: epidemiology, risk factors, and health services. Clin Colon Rectal Surg, 18, 133-40.

Amin TT, Suleman W, Ali A, et al (2011). Pattern, prevalence, and perceived personal barriers toward physical activity among adult Saudis in Al-Hassa, KSA. J Phys Act Health, 8, $775-84$.

Aparna K (2014). The knowledge, attitudes and practices approach: an evaluation of the barriers to colorectal cancer screening at Orange Blossom Family Health Johns Hopkins University School of Medicine, 2014. PCLPSite: Health Care Center for the Homeless, Orange Blossom Family Health, Orlando.

Berkowitz Z, Hawkins NA, Peipins LA, et al (2008). Beliefs, risk perceptions, and gaps in knowledge as barriers to colorectal cancer screening in older adults. J Am Geriatr Soc, 56, 307-14.
Bidouei F, Abdolhosseini S, Jafarzadeh N, et al (2014). Knowledge and perception toward colorectal cancer screening in east of Eran. Int J Health Policy Manag, 3, 11-15.

Center MM, Jemal A, Smith RA, et al (2009). Worldwide variations in colorectal cancer. CA Cancer J Clin, 59, 366-78.

Christou A and Thompson S (2012). Colorectal cancer screening knowledge, attitudes and behavioural intention among Indigenous Western Australians. BMC Public Health, 12, 528.

Christy S, Perkins S, Tong Y, et al (2013).Promoting colorectal cancer screening discussion: a randomized controlled trial. Am J Prev Med, 44, 325-29.

Cronbach LJ (1951). Coefficient alpha and the internal structure of tests. Psychometrika, 16, 297-334.

Demyati E (2014). Knowledge, attitude, practice, and perceived barriers of colorectal cancer screening among family physicians in National Guard Health Affairs, Riyadh. Int $J$ Family Med, 2014, 457354.

Federici A, Rossi PG, Bartolozzi F, et al (2005). Survey on colorectal cancer screening knowledge, attitudes, and practices of general practice physicians in Lazio, Italy. Prev Med, 41, 30-35.

Gimeno Garcia AZ (2012). Factors influencing colorectal cancer screening participation. Gastroenterol Res Pract, 2012, 483417.

Hair JFJ, Anderson RE, Tatham RL, et al (1998). Multivariate data analysis. 5th ed. Prentice Hall; Upper Saddle River, NJ.

Hay JL, Ford JS, Klein D, et al (2003). Adherence to colorectal cancer screening in mammography-adherent older women. J Behav Med, 26, 553-76.

Hoffman RM, Rhyne RL, Helitzer DL, et al (2011). Barriers to colorectal cancer screening: physician and general population perspectives, New Mexico, 2006. Prev Chronic Dis, $8,35$.

James A, Daley C, Greiner K (2011). Knowledge and attitudes about colon cancer screening among African Americans. Am $J$ Health Behav, 35, 393-401.

James AS, Campbell MK, Hudson MA (2002). Perceived barriers and benefits to colon cancer screening among African Americans in in North Carolina: How does perception relate to screening behavior? Cancer Epidemiol Biomarkers Prev, 11, 529-34.

Jones R, Devers K, Kuzel A, et al (2010a). Patient-reported barriers to colorectal cancer screening: a mixed-methods analysis. Am J Prev Med, 38, 508-16.

Jones RM, Woolf SH, Cunningham TD, et al (2010b). The relative importance of patient-reported barriers to colorectal cancer screening. Am J Prev Med, 38, 499-507.

Joseph DA, King JB, Miller JW, et al (2012). Prevalence of colorectal cancer screening among adults-behavioral risk factor surveillance system, United States, 2010. Morb Mortal Wkly Rep, 61, 51-6.

Khayyat YM and Ibrahim EM (2014). Public awareness of colon cancer screening among the general population: a study from the Western Region of Saudi Arabia. Qatar Med $J, 2014,17-24$.

Kim J and Mueller C (1978). Factor analysis: statistical methods and practical issues. Newbury Park, CA: Sage Publications.

Klabunde CN, Schenck AP, Davis WW (2006). Barriers to colorectal cancer screening among Medicare consumers. Am J Prev Med, 30, 313.

Koo JH, Arasaratnam MM, Liu K, et al (2010). Knowledge, perception and practices of colorectal cancer screening in an ethnically diverse population. Cancer Epidemiol, 34, 604-10.

Koo JH, Leong RW, Ching J, et al (2012). Knowledge of, attitudes toward, and barriers to participation of colorectal 
Yasmine Samir Galal et al

cancer screening tests in the Asia-Pacific region: a multicenter study. Gastrointest Endosc, 76, 126-35.

Lozano R, Naghavi M, Foreman K, et al (2012). Global and regional mortality from 235 causes of death for 20 age groups in 1990 and 2010: a systematic analysis for the Global Burden of Disease Study 2010. Lancet, 380, 2095-128.

Mack LA, Stuart H, Temple WJ (2004).Survey of colorectal cancer screening practices in a large Canadian urban centre. Can J Surg, 47, 189-94.

McQueen A, Vernon S, Myers R, et al (2007). Correlates and predictors of colorectal cancer screening among male automotive workers. Cancer Epidemiol Biomarkers Prev, 16, 500-9.

McVeigh TP, Lowery AJ, Waldron RM, et al (2013). Assessing awareness of colorectal cancer symptoms and screening in a peripheral colorectal surgical unit: a survey based study. BMC Surg, 13, 20.

Merika E, Saif MW, Katz A, et al (2010). Review. Colon cancer vaccines: an update. In Vivo, 24, 607-28.

Miller D, Brownlee C, McCoy T, et al (2007). The effect of health literacy on knowledge and receipt of colorectal cancer screening: a survey study. BMC Fam Pract, 8, 16.

Mosli M and Al-Ahwal M (2012). Colorectal cancer in the Kingdom of Saudi Arabia: need for screening. Asian Pac J Cancer Prev, 13, 3809-76.

NG S and Wong S (2013). Colorectal cancer screening in Asia. Br Med Bull, 105, 29-42.

Puteh S, Khairudin S, Kabinchong C, et al (2014). Relationship of knowledge, attitude, practice (KAP) and demographic factors with quality of life among urban colorectal cancer patients in Malaysia. Middle East J Cancer, 5, 31-41.

Ravichandran K, Al-Hamdan N, Mohamed G (2011). Knowledge, attitude, and behavior among Saudis toward cancer preventive practice. J Family Community Med, 18, 135-42.

Sessa A, Abbate R, Di Giuseppe G, et al (2008). Knowledge, attitudes, and preventive practices about colorectal cancer among adults in an area of Southern Italy. BMC Cancer, $\mathbf{8}, 171$.

Singh H, Bernstein C, Samadder J, et al (2015). Screening rates for colorectal cancer in Canada: a cross sectional study. CMAJ Open, 3, 149-57.

Sun WY, Basch CE, Wolf RL, et al (2004). Factors associated with colorectal cancer screening among Chinese-Americans. Prev Med, 39, 323-9.

Sung JJ, Choi SY, Chan FK, et al (2008). Obstacles to colorectal cancer screening in Chinese: a study based on health belief model. Am J Gastroenterol, 103, 974-81.

Sung JJ, Lau JY, Goh KL, et al (2005). Increasing incidence of colorectal cancer in Asia: implications for screening. Lancet Oncol, 6, 871-76.

Van Jaarsveld CH, Miles A, Edwards R, et al (2006). Marriage and cancer prevention: does marital status and inviting both spouses together influence colorectal cancer screening participation? J Med screen, 13, 172-6.

Wee CC, McCarthy EP, Phillips RS (2005). Factors associated with colon cancer screening: the role of patient factors and physician counseling. Prev Med, 41, 23.

Wong R, Wong M, Chan Y, et al (2013). Gender differences in predictors of colorectal cancer screening uptake: a national cross sectional study based on the health belief model. BMC Public Health, 13, 677.

Zauber AG, Winawer SJ, O Brien MJ, et al (2012).Colonoscopic polypectomy and long-term prevention of colorectal-cancer deaths. $N$ Engl J Med, 366, 687-96.

Zubaidi A, AlSubaie N, AlHumaid A, et al (2015). Public awareness of colorectal cancer in Saudi Arabia: a survey of 1070 participants in Riyadh. Saudi J Gastroenterol, 21, 78-83. 